\title{
Is Previous Pregnancy Affected By Diabetes Mellitus Protective against Poor Glycemic Control at the Start of Subsequent Pregnancies?
}

Mulla $\mathrm{BM}^{*}$ and Zelig CM

Department of Obstetrics and Gynecology, Naval Medical Center Portmouth, USA

\begin{abstract}
Aims/hypothesis: Poor glycemic control at conception, a strong risk factor for birth defects, is frequently attributed to low rates of pre-conceptual counseling. The objective of this study was to determine if counseling during a first pregnancy with diabetes improved glycemic control at conception in subsequent pregnancies.

Methods: Case controlled. 71 diabetic women previously followed during pregnancy at a single tertiary center were divided into two groups, those with diabetes at the start of a previous pregnancy, and those without. The two groups were compared for glycemic control at conception; hemoglobin $A_{1 C} \geq 7$ was considered poor control. The two groups were also compared for very poor control (hemoglobin $A_{1 C} \geq 9$ ), pre-conceptual counseling, and pre-
\end{abstract} conceptual folic acid use.

Results: Poor glycemic control at conception was as prevalent in the 29 previous diabetic patients as in the 42 first-time diabetic patients $(51.7 \%$ vs. $57.1 \%, p=0.7)$. There was no difference in the proportion of diabetic patients with very poor control $(17.2 \%$ vs. $23.8 \%, p=0.5)$, pre-conceptual counseling $(6.9 \%$ vs. $4.8 \%, p=1.0)$ and folic acid use $(32.1 \%$ vs. $31.0 \%, p=0.9)$.

Conclusions/interpretation: Previous pregnancy affected by diabetes did not improve glycemic control in a subsequent pregnancy. Expanding the counseling these patients receive in our institution should be considered.

Keywords: Pregnancy; Diabetes; Hemoglobin $\mathrm{A}_{1 \mathrm{C}}$

\section{Introduction}

There is an increased rate of serious birth defects in the offspring of diabetic women. These birth defects include anomalies of the fetal central nervous, cardiac, skeletal and renal systems. Evidence for this effect is a well established relationship between the maternal serum $\mathrm{HbA}_{1 \mathrm{C}}$ level in early pregnancy, the main period of organogenesis; and congenital anomalies in the offspring of that pregnancy. Cutoff values for early $\mathrm{HbA1C}$ and risk of major congenital malformations are: $\mathrm{HbA}_{1 \mathrm{C}}$ $<7,2-3 \%, \mathrm{HbA}_{1 \mathrm{C}}$ of 7-8.9, 5-10\%; 9-10.9, 10-20\%; $\geq 11,>20 \%$ [1-4].

Many pregnancies in the United States are unplanned and therefore lack preconceptual planning. In diabetic women, such planning focuses on good glycemic control before conception with a targeted $\mathrm{HbA}_{1 \mathrm{C}}$ of less than 7 in order to minimize the risk of birth defects. In a prospective cohort trial, preconceptual counseling of diabetic patients was associated with an improvement in the proportion of patients with optimal glycemic control from $40 \%$ in the group with no preconceptual counseling to $81 \%$ in those with preconceptual counseling [5]. For many diabetic women, their first regular exposure to an obstetrician does not occur until their first pregnancy is well underway. Since it is a routine part of obstetrical care to counsel diabetic patients about the importance of good glycemic control, it is possible that maternal $\mathrm{HbA}_{1 \mathrm{C}}$ levels at the start of subsequent pregnancies would be lower than in the first pregnancy affected by diabetes. That is, education of diabetic patients by their obstetrician during a first affected pregnancy should theoretically result in better pre-conceptual planning and better glycemic control at the start of subsequent pregnancies. A study by Rosenn et al. noted significantly improved glycohemoglobin concentrations at 9 and 14 weeks gestation in insulin-dependent diabetic patients who received counseling for two consecutive pregnancies compared with those who entered a counseling program for the first time [6]. Another study looked at the protective effect of previous pregnancy on glycemic control during the entire gestational period of subsequent gestations, but was underpowered to measure changes in $\mathrm{HbA}_{1 \mathrm{C}}$ levels in early gestation [7]. A third study looked at the glycemic control in early pregnancy of African American patients with type 1 diabetes, of which a significant difference of $\mathrm{HbA}_{1 \mathrm{C}}$ based on parity was present, but this was not the primary objective of the study [8].

If glycemic control is not improved in subsequent pregnancies, prenatal education by obstetricians may need to be changed to better prepare their patients for future conceptions. Additionally, counseling between pregnancies by the patient's other healthcare providers may need to be adjusted.

\section{Methods}

We conducted a retrospective case-control study of diabetic women who received prenatal care at our center from 2003 to 2010 . The study was approved by the Institutional Review Board of Naval Medical Center Portsmouth. Data were derived from our electronic medical record system and from our delivery logs. Patients were identified by the diagnosis of diabetes mellitus at the start of the subject gestation, from ICD-9 or equivalent diagnosis codes.

There were a total of 120 patients in the database; 71 met inclusion criteria for our study. Patients were excluded if they did not have a hemoglobin $\mathrm{A}_{1 \mathrm{C}}$ during the peri-conceptual period, i.e. between 3

*Corresponding author: Mulla BM, 620 John Paul Jones Circle, Portsmouth, VA USA, Tel: 757-953-4351; Fax: 757-953-0892; E-mail: bethany.mulla@med.navy.mil

Received June 09, 2012; Accepted July 18, 2012; Published July 24, 2012

Citation: Mulla BM, Zelig CM (2012) Is Previous Pregnancy Affected By Diabetes Mellitus Protective against Poor Glycemic Control at the Start of Subsequent Pregnancies? J Diabetes Metab 3: 205. doi:10.4172/2155-6156.1000205

Copyright: ( 2012 Mulla BM, et al. This is an open-access article distributed under the terms of the Creative Commons Attribution License, which permits unrestricted use, distribution, and reproduction in any medium, provided the original author and source are credited. 
months preconception and 14 weeks post-conception, and if they did not receive prenatal care at our facility. If a patient had more than one affected pregnancy, she was counted for the most recent pregnancy only. Patients who received prenatal care but did not deliver at our facility were still counted as part of the study.

For each subject, the following data was extracted: maternal age, race and parity, singleton or twin gestation, pre-pregnancy height, weight, BMI, age at diagnosis of diabetes, duration of diabetes, method of control, co-morbid medical conditions, number of previous pregnancies complicated by diabetes, $\mathrm{HbA}_{1 \mathrm{C}}$ level between 3 months preconception and 14 weeks post-conception, presence or absence of folic acid use starting more than one month prior to conception, presence or absence of nutrition consult prior to pregnancy, mode of delivery, and birth weight. If the patient had more than one $\mathrm{HbA}_{1 C}$ level drawn meeting our study criteria, the one drawn closest to the time of conception was used. The patients were also classified based on presence or absence of insulin therapy prior to pregnancy. Patients who received prenatal care but did not deliver at our facility were still counted as part of the study however infant birth weight and mode of delivery were not recorded for those patients.

The patients were divided into two groups for comparison. The first group consisted of patients being followed for their first pregnancy with pre-existing diabetes; the second group was comprised of patients with type 1 or type 2 diabetes during a previous pregnancy. The primary outcome measure was the presence or absence of poor glycemic control during the peri-conceptual period. Well-controlled diabetic patients were defined as having a hemoglobin $A_{1 C}$ less than 7 and poorly controlled diabetic patients were defined as a hemoglobin $A_{1 C}$ greater than or equal to 7 . Very poor glycemic control was defined as having a hemoglobin $\mathrm{A}_{1 \mathrm{C}}$ greater than or equal to 9. Secondary outcome measures were very poor peri-conceptual glycemic control, use of preconceptual counseling, use of pre-conceptual folic acid for at least one month before conception, mode of delivery, and birth weight. We hypothesized that patient education during a previous pregnancy better prepares diabetic patients for subsequent pregnancies as demonstrated by better glycemic control at conception of the subsequent pregnancies.

Statistics were carried out using the Open Epi.com web site from the Center for Disease Control and Prevention (CDC). Categorical variables were compared using a two sided Chi-squared statistic and continuous variables were compared using a two-sided Student $t$ test. Based on a previous study [5], we powered our study to detect an increase in the proportion of patients with good glycemic control from $40 \%$ to $81 \%$. Using a beta of 0.2 and an alpha of 0.05 , a minimum of 27 subjects was needed in each arm [9].

\section{Results}

For the 71 subjects studied, poor glycemic control at conception was as prevalent in the 29 previous diabetic patients as in the 42 first time diabetic patients $(51.7 \%$ vs. $57.1 \%, \mathrm{p}=0.7)$. Also, there were no differences in the proportion of patients with very poor glycemic control $(17.2 \%$ vs. $23.8 \%, \mathrm{p}=0.5)$, pre-conceptual counseling $(3.4 \%$ vs. $14.3 \%, \mathrm{p}=0.16)$ and pre-conceptual folic acid use (31.0 \% vs $31.0 \%$, $\mathrm{p}=0.99)$ (Table 1).

In patients not requiring insulin prior to pregnancy, there was a non-significant trend towards better glycemic control, i.e. fewer patients with poor glycemic control, in the previous diabetic pregnancy group compared to the first time diabetic pregnancy group (18\% vs.

\begin{tabular}{|l|l|l|}
\hline & $\begin{array}{l}\text { First pregnancy with } \\
\text { diabetes }\end{array}$ & $\begin{array}{l}\text { Second or greater } \\
\text { pregnancy with } \\
\text { diabetes }\end{array}$ \\
\hline Number of subjects & 42 & 29 \\
\hline Maternal age (years) & $28.3 \pm 5.1$ & $29.8 \pm 5.4$ \\
\hline $\begin{array}{l}\text { Maternal race } \\
\text { Caucasian }\end{array}$ & $26(62 \%)$ & $11(38 \%)$ \\
African-American & $8(19 \%)$ & $8(28 \%)$ \\
Asian/Pacific Islander & $0(0 \%)$ & $1(3 \%)$ \\
Other & $6(14 \%)$ & $6(21 \%)$ \\
Unknown & $2(5 \%)$ & $3(10 \%)$ \\
\hline $\begin{array}{l}\text { Body mass index at conception } \\
\text { (kg/m²) }\end{array}$ & $30.4 \pm 7.1$ & $31.7 \pm 7.8$ \\
\hline Age at diagnosis (years) & $22.4 \pm 9.4$ & $19.1 \pm 8.8$ \\
\hline Control of diabetes & $4(10 \%)$ & $2(7 \%)$ \\
Diet & $22(53 \%)$ & $8(28 \%)$ \\
Oral medication & $10(24 \%)$ & $9(31 \%)$ \\
Insulin shots & $6(13 \%)$ & $10(34 \%)$ \\
Insulin pump & $17(40 \%)$ & $18(62 \%)$ \\
\hline Type of diabetes & & $11(38 \%)$ \\
\hline Insulin use prior to pregnancy & $25(60 \%)$ & \\
No insulin use prior to pregnancy & & \\
\hline
\end{tabular}

aThere was no statistically significant between the two groups, however there was a non-significant trend towards a higher proportion of patients taking insulin prior to pregnancy in the second or greater pregnancy with diabetes group compared to the group with their first diabetic pregnancy $(p=0.08)$

Table 1: Characteristics of patients by number of pregnancies with diabetes.

\begin{tabular}{|l|l|l|l|l|}
\hline & $\begin{array}{l}\text { First pregnancy } \\
\text { with diabetes }\end{array}$ & $\begin{array}{l}\text { Second } \\
\text { or greater } \\
\text { pregnancy with } \\
\text { diabetes }\end{array}$ & $\begin{array}{l}\text { Odds Ratio } \\
(95 \% \text { CI) }\end{array}$ & P \\
\hline $\begin{array}{l}\text { Hemoglobin A1C } \\
\text { (mean } \pm \text { standard } \\
\text { deviation) }\end{array}$ & $7.7 \pm 1.9$ & $7.4 \pm 1.6$ & NS \\
\hline Hemoglobin A1C $\geq 7$ & $57.1 \%$ & $51.7 \%$ & $0.80(0.31-2.1)$ & NS \\
\hline Hemoglobin A1C $\geq 9$ & $23.8 \%$ & $17.2 \%$ & $0.67(0.20-2.2)$ & NS \\
\hline $\begin{array}{l}\text { Preconceptual coun- } \\
\text { seling }\end{array}$ & $14.3 \%$ & $3.4 \%$ & $0.21(0.02-1.9)$ & NS \\
\hline $\begin{array}{l}\text { Preconceptual folic } \\
\text { acid }\end{array}$ & $31.0 \%$ & $31.0 \%$ & $1.0(0.4-2.8)$ & NS \\
\hline $\begin{array}{l}\text { No insulin prior to } \\
\text { pregnancy }\end{array}$ & $48 \%$ & $18 \%$ & $0.24(0.4-1.3)$ & NS \\
\hline $\begin{array}{l}\text { Insulin prior to preg- } \\
\text { nancy }\end{array}$ & $71 \%$ & $72 \%$ & $1.1(0.25-4.7)$ & NS \\
\hline Cesarean delivery & $62.2 \%$ & $62.5 \%$ & $1.0(0.4-2.9)$ & NS \\
\hline $\begin{array}{l}\text { Birth weight, g (mean } \\
\pm \text { standard deviation) }\end{array}$ & $3512 \pm 750$ & $3422 \pm 616$ & & NS \\
\hline
\end{tabular}

bThere was a non-significant trend towards better glycemic control (smaller proportion of patients with poor control) in the no insulin patients with previously affected pregnancies compared to the no insulin patients in their first affected pregnancy $(p=0.1)$

Table 2: Primary and secondary outcome measures of first versus second or greater pregnancy with diabetes.

$48 \%, \mathrm{p}=0.1$ ). Previous diabetic pregnancy was not protective against poor glycemic control at conception in diabetic women taking insulin prior to pregnancy $(72 \%$ vs. $71 \%, \mathrm{p}=1.0)$. In addition, previous diabetic pregnancy was not protective against very poor glycemic control (hemoglobin $A_{1 C} \geq 9$ ) in either subgroup. These results are summarized in (Table 2).

Patients who required insulin prior to pregnancy were more likely than those not requiring insulin to have poor control $(71 \%$ vs. $39 \%$, $\mathrm{p}<0.01)$ but not very poor control $(23 \%$ vs. $19 \%, \mathrm{p}=0.7)$. These results are summarized in (Table 3 ). There was a significantly higher proportion of patients with pre-pregnancy insulin use within the group with 


\begin{tabular}{|l|l|l|l|l|}
\hline & $\begin{array}{l}\text { Insulin prior to } \\
\text { pregnancy }\end{array}$ & $\begin{array}{l}\text { No insulin prior to } \\
\text { pregnancy }\end{array}$ & $\begin{array}{l}\text { Odds Ratio (95\% } \\
\mathrm{Cl})\end{array}$ & $\mathrm{p}$ \\
\hline $\begin{array}{l}\text { Hemoglobin } \\
\mathrm{A}_{1 \mathrm{CC}} \geq 7\end{array}$ & $25(71 \%)$ & $14(39 \%)$ & $3.9(1.5-10.6)$ & $<0.01$ \\
\hline $\begin{array}{l}\text { Hemoglobin } \\
\mathrm{A}_{1 \mathrm{C}} \geq 9\end{array}$ & $8(23 \%)$ & $7(19 \%)$ & $1.2(0.39-3.8)$ & NS \\
\hline
\end{tabular}

Table 3: Glycemic control at conception among insulin versus non insulin requiring diabetic patients.

previously affected pregnancies than in the group of first time diabetic pregnancies $(62 \%$ vs. $40 \%, \mathrm{p}<0.01)$.

\section{Discussion}

In our study, glycemic control at conception was no better in experienced diabetic patients, those with a history of diabetes predating one or more prior gestations; than in novices, those with their first diabetic pregnancy. Poor glycemic control in the novice group is not surprising given the low rate of pre-conceptual counseling we and others have observed. The equally poor glycemic control at conception in the experienced diabetic patients was unexpected since all of these patients should have received counseling from their obstetrician during and after previously affected pregnancies. A potential effect modifier in this study was the patients requiring insulin prior to pregnancy, who comprised nearly half of our subjects. In this group, there was a high prevalence of poor glycemic control at conception in novice and experienced patients, $71 \%$ and $72 \%$ respectively. This may reflect the generally more severe underlying disease in type 1 diabetic patients and type 2 diabetic patients requiring insulin when not pregnant compared to non-insulin dependent type 2 diabetic patients of childbearing age. By comparison, we observed a trend towards improved glycemic control in the experienced patients requiring insulin prior to pregnancy compared to the novice patients not requiring insulin prior to pregnancy. It is possible that this result would have been more significant if our study population had been predominantly type 2 diabetic patients.

We recognize that increased birth defects can occur at $\mathrm{HbA}_{1 \mathrm{C}}$ values below 7 , and that there is no true threshold value below which the risk of congenital anomalies is eliminated. However, the increase in birth defects is minimal with $\mathrm{HbA}_{1 \mathrm{C}}$ values below 7 in most studies $[10,11]$. Clinical guidelines that existed during the study period used $<7$ as a target $\mathrm{HbA}_{1 \mathrm{C}}$ for women attempting conception $[12,13]$. The decision to use $\mathrm{HbA}_{1 \mathrm{C}}$ values from 3 months before pregnancy until 14 weeks postconception reflects the traditional study period for teratogenic effects. Since $\mathrm{HbA}_{1 \mathrm{C}}$ values reflect 2-3 months of average glycemic control, this time frame provides reasonable accuracy of peri-conceptual risk.

A weakness of our study is its retrospective design and the inherent problem of confounders that can result. Therefore, we cannot assume that all differences in glycemic control in our study groups were the result of pre-conceptual counseling during a previously affected pregnancy. Other factors that could affect our results would include duration of diabetes, maternal activity level as well as more intangible, difficult to measure metrics such as maternal psychosocial stressors. For example, patients in their second diabetic pregnancy are more likely to be caring for small children during the peri-conception period than nulliparous patients, which could certainly add to the challenges of achieving good glycemic control. Indeed, the "experienced" diabetic patients in our study tended to be slightly older and heavier than the patients in their first diabetic pregnancy. It is difficult to determine if the sum of these effects acted synergistically to affect glycemic control, even if differences in the individual factors were not statistically significant. Comparison of glycemic control in the same diabetic patient from one pregnancy to the next would correct for some of the more significant demographic confounders but still would not adjust for temporal changes such as increased child-care responsibilities as the patient's family size increases. Finally, many of our patients were seen by non-obstetric providers such as family practitioners, internists and endocrinologists before and between gestations, which could have affected our results.

Our mean hemoglobin $A_{1 C}$ near the time of conception was comparable to other studies, in which the mean hemoglobin $\mathrm{A}_{1 \mathrm{C}}$ varied from 6.56 to $9.5[2,3,5,8]$. Therefore, with regards to baseline glycemic control, our patients are comparable to the general diabetic patient population. One factor which did not affect our findings was limitations in access to care. Within the military setting, all patients receive free healthcare, including preconception and nutritional counseling as well as free medications and diabetes supplies. Also, obstetricians in our center cousel women using standard American College of Obstetrics and Gynecology guidelines for glycemic control before and during pregnancy $[14,15]$.

The findings in our study highlight the need for pre-conceptual planning in fertile diabetic women. A multidisciplinary team approach consisting of the patient's primary care physician, endocrinologist, obstetrician and any other healthcare providers should be considered. In addition, different strategies may be needed for patients requiring insulin prior to pregnancy, since, on average; these patients tend to have worse glycemic control and may represent a sicker, more difficult group to treat.

\section{Contribution Statement}

B.M. is the guarantor of this work and, as such, had full access to all the data in the study and takes responsibility for the integrity of the data and the accuracy of the data analysis.

B.M. researched data and wrote the manuscript. C.Z. contributed to the discussion and reviewed/edited the manuscript.

\section{Acknowledgement}

The views expressed in this article are those of the author(s) and do not necessarily reflect the official policy or position of the Department of the Navy, Department of Defense or the United States Government.

I am a military service member. This work was prepared as part of my official duties. Title 17 U.S.C. 105 provides that 'Copyright protection under this title is not available for any work of the United States Government.' Title 17 U.S.C. 101 defines a United States Government work as a work prepared by a military service member or employee of the United States Government as part of that person's official duties.

Research data derived from an approved Naval Medical Center, Portsmouth, VA IRB protocol.

\section{References}

1. Schaefer-Graf UM, Buchanan TA, Xiang A, Songster G, Montoro M, et al (2000) Patterns of congenital anomalies and relationship to initial maternal fasting glucose levels in pregnancies complicated by type 2 and gestational diabetes. Am J Obstet Gynecol 182: 313-320.

2. Suhonen L, Hiilesmaa V, Teramo K (2000) Glycaemic control during early preg nancy and fetal malformations in women with Type I diabetes mellitus. Diabetologia 43: 79-82.

3. Gold AE, Reilly R, Little J, Walker JD (1998) The effect of glycemic control in the pre-conception period and early pregnancy on birth weight in women with IDDM. Diabetes Care 21: 535-538.

4. Berghella V (2007) Pregestational and gestational diabetes. Maternal-Fetal Evidence Based Guidelines, Informa Healthcare, London: 43-55.

5. Kitzmiller JL, Gavin LA, Gin GD, Jovanovic-Peterson L, Main EK, et al. (1991) 
Citation: Mulla BM, Zelig CM (2012) Is Previous Pregnancy Affected By Diabetes Mellitus Protective against Poor Glycemic Control at the Start of Subsequent Pregnancies? J Diabetes Metab 3: 205. doi:10.4172/2155-6156.1000205

Page 4 of 4

Preconception care of diabetes. Glycemic control prevents congenital anomalies. JAMA 265: 731-736

6. Rosenn B, Miodovnik M, Mimouni F, Khoury JC, Siddiqi TA (1991) Patient experience in a diabetic program project improves subsequent pregnancy outcome. Obstet Gynecol 77: 87-91.

7. Vaarasmaki M, Anttila M, Pirttiaho H, Hartikainen AL (2002) Are recurrent pregnancies a risk in type I diabetes? Acta Obstet Gynecol Scand 81: 1110-1115.

8. Holcomb WL Jr, Mostello DJ, Leguizamon GF (2001) African-American women have higher initial HbA1c levels in diabetic pregnancy. Diabetes Care 24: 280 283.

9. Hulley SB, Cummings SR, Browner WS, Grady DG (2007) Newman TB Designing Clinical Research. ( $3^{\text {rd }}$ edn) Lippincott Williams and Wilkins, Philadelphia.

10. Walkinshaw SA (2005) Pregnancy in women with pre-existing diabetes: Management issues. Semin Fetal Neonatal Med 10: 307-315.
11. Eidem I, Stene LC, Henriksen T, Hanssen KF, Vangen S, et al. (2010) Congenital anomalies in newborns of women with type 1 diabetes: nationwide population-based study in Norway, 1999-2004. Acta Obstet Gynecol Scand 89: 1403-1411.

12. American Diabetes Association (2009) Standards of medical care in diabetes--2009. Diabetes Care 32: S13-S61.

13. Kitzmiller JL, Block JM, Brown FM, Catalano PM, Conway DL, et al. (2008) Managing preexisting diabetes for pregnancy: summary of evidence and consensus recommendations for care. Diabetes Care 31: 1060-1079.

14. ACOG Committee on Practice Bulletins (2005) ACOG Practice Bulletin. Clinical Management Guidelines for Obstetrician-Gynecologists. Number 60, March 2005. Pregestational diabetes mellitus. Obstet Gynecol 105: 675-685.

15. Gabbe SG, Graves CR (2003) Management of diabetes mellitus complicating pregnancy. Obstet Gynecol 102: 857-868. 